\title{
The Use of English and Code Switching in the Teaching and Learning of Technology in some Schools in Eastern Cape Province, South Africa
}

\author{
Moses Makgato \\ Tshwane University of Technology, Department of Educational Studies
}

Doi:10.5901/mjss.2014.v5n23p933

\begin{abstract}
English is the language of learning and teaching in many schools in South Africa. The ability of teachers and students to understand and communicate with each other in English contributes to better performance in Science and Technology subjects. This article explores the challenges posed by the use of English in the teaching and learning of Technology subject at schools in Eastern Cape and the role of code switching as a strategy to facilitate pedagogic communication between teachers and learners. The study was undertaken in order to clarify the commonality of problems related to the use of English and the use of code switching to transmit lesson content in the ESL classroom. The sample for the questionnaire comprised 57 teachers who taught Technology at different schools in the school district of Eastern Cape province. Semi-structured interviews were also conducted with five subject specialists in Technology. The findings revealed that the use of English militates against effective learning and teaching of Technology. It was also found that code switching to L1 (isiXhosa) is a common practice in order to sustain continuous communication between teachers and learners. In order to enhance the communication skills of students, it is recommended that teachers increase dialogue in English by means of small-group discussion, exploratory talk and argumentation.
\end{abstract}

Keywords: Technology; language, challenges, Eastern Cape, ESL,LoLT

\section{Introduction}

In the history of South Africa, language-in education policy has always been full of a controversy, tensions, contradictions, and sensitivities underpinned by racial and linguistic discriminations (Alexander, 2001). The new language in education policy is conceived as an integral and necessary aspect of the new government's strategy of building a non-racial society in South Africa. The policy is meant to facilitate communication across the barriers of colour, language and region, while at the same time creating an environment in which respect for languages other than one's own would be encouraged (Dalvit and de Klerk, 2005). It appears that coupling mother-tongue instruction with an impoverished curriculum in 'black' schools (see Wright, 1996), has had devastating effects on the education of the speakers of African languages, of which the consequences still exist today (ibid). Heugh (2000) argues that the current language policy perpetuates the exclusion from power of speakers of African languages. In fact, as noted by Webb and Kembo- Sure (2000), black students are disadvantaged by their lack of English proficiency. The language policy in education is seen to be in line with the fact that both societal and individual multilingualism are the global norm today, especially on the African continent. As such, it assumes that the learning of more than one language should be general practice and principle in our society. That is, being multilingual should be a defining characteristic of being South African. This is introduced also to counter any particularistic ethnic chauvinism or separatism through mutual understanding. .A wide spectrum of opinions exists as to the locally viable approaches towards multilingual education, ranging from arguments in favour of the cognitive benefits and cost-effectiveness of teaching through one medium (home language) and learning additional language(s) as subjects, to those drawing on comparative international experience demonstrating that, under appropriate conditions, most learners benefit cognitively and emotionally from the type of structured bilingual education found in dual-medium (also known as two way immersion) programmes. Whichever route is followed, the underlying principle is to maintain home language(s) while providing access to and the effective acquisition of additional language(s). Hence, the Department of Education's position that an additive approach to bilingualism is to be seen as the normal orientation of our language-in-education policy. It is not clear currently, whether the language in education policy will enable African 'black' language speakers to be proficiency in English which is LolT in many 'black' African schools. Dlamini (2001) notes that most black students are not proficient in English when they get to university, and they have to work harder than white students because they have to grapple with the language of instruction as well as with the concepts taught. This might be one of the reasons for the poor performance of many speakers of African languages at schools and universities, in subjects such as mathematics and sciences (Dalvit and de Klerk, 2005). After the recognition of 11 official languages in the new South African Constitution (Act No. 108 of 1996), the challenge for the education system has been to strike a balance between the use of the formerly dominant language, English and the mother tongue as LolT. In the ongoing 
debate about which LolT is more appropriate for speakers of an African language, arguments have been put forward to support both an English-mainly or English-only policy (see Titlestad, 1996) and a bilingual (English and mother tongue) approach (see Luckett, 1995; Heugh, 2000). As it will be seen in this study, most of the challenges in English communication and interactions between learners and teachers in classrooms occurs in rural schools. Neeta and Klu (2013) argue that the problem of a lack of vital skills in second language education has been exacerbated by the framework used in policy documents for education which do not provide adequate support for rural areas that tend to lag behind urban areas. The fact that rural education has not been a priority of the post-apartheid government has resulted in an educational framework used in policy documents that is insufficiently cognisant to the specific conditions and needs of the rural poor. For instance, high school teachers more often than not, do not possess adequate proficiency in the English language for effective teaching and learning to take place and as such these teachers feel inadequate and unequipped to take charge of their teaching. As a result, they use very little English; use it incorrectly, or resort to home languages, a phenomenon known as code switching (ibid).

Effective learning depends on the ability of teachers to communicate in a manner that is comprehensible to students. The most important function of education is that teaching should result in effective learning. Furthermore, learners should be able to seek knowledge through communication with their peers, reading and research. However, despite the fact that the language of instruction is English, communication between learners and teachers is easier when the mother tongue or any African language is spoken, as in many South African schools (Alidou \& Maman, 2003; BrockUtne, 2005). In many schools in South Africa, learners begin to read and write in English in Grade 4. A popular belief is that the sooner the child is exposed to English in the classroom, the better he/she will learn the language. To date, many studies that have been conducted in Africa and abroad have indicated that learners perform poorly in mathematics and sciences because of the use of a second language as a medium of instruction (Mekonnen, 2005; Wilmot, 2003; FreduaKwarteng \& Ahia, 2005; Reddy, 2005). In addition, the Language in Education Policy (LiEP) is not monitored by the Department of Education, and consequently it is not properly implemented in schools.

This article is an exegesis of the challenges posed by the use of English in the teaching and learning of Technology in schools. The survey was undertaken in order to clarify the commonality of problems related to the use of English. This study draws from existing studies on the problems regarding the use of English as a language of learning and teaching (LoLT) in mathematics and science (see Setati \& Barwell, 2006; Probyn, 2004; Setati \& Adler, 2001; Dutcher, 2004). These were mostly longitudinal studies that focused on one to six classes. The recurring failure rate of Grade 12 learners in mathematics, science and technology subjects calls for a concerted effort to improve not only their understanding of the subject, but also their ability to use English in the teaching and learning context. Studies that involve a large number of schools, particularly in other related subjects, are important in order to understand the scope of the barriers of using English in teaching and learning. The majority of South African learners cannot express their understanding of the subject through English, which is the language of instruction (Probyn, 2006). In their study, Myburg, Poggenpoel and Van Rensburg (2004) found that learners do not accept the language of teaching as their own. While technology is imbued with its own 'language' or terminology, concepts are explained in English by the teacher because it is the LoLT in schools.

There are many problems in schools today that render the learning and teaching process difficult. The use of English in teaching and learning science and technology subjects is one of the factors that contribute to the poor performance of learners in schools (Ferreira, 2011: 102). Serious communication and learning problems are faced daily by teachers and learners in African classrooms. Brock-Utne, Desai \& Qorro (2004) argue that most African teachers experience difficulty in presenting subject matter in English, owing to their lack of fluency.

The purpose of this article is to shed light on the scope of the barriers caused by the use of English in teaching and learning technology subjects in schools. In this article, the terms 'students' and 'learners' are used alternately. The terms educator and teacher are also used interchangeably.

\section{Literature Review}

\subsection{English as a language of teaching and learning}

English, to a large extent, has escaped the antagonism that was directed towards the ex-colonial languages, as most language education policy proposals envisaged a central place for English (Alidou, Boly Brock-Utne, Diallo, Heugh \& Wolf, 2006). Heugh (2000) states that the primary goal of bilingualism proposed by the National Language Project is that English and one dominant regional language will be used for teaching. There is a continuous reduction of the use of early mother tongue as the language of teaching and learning in many South African schools. According to Muyeeba (2004), the latest change in language policy has resulted in a continuation of English as the LoLT during earlier school years. 
African languages such as isizulu, seSotho and tshiVenda are used only for initial literacy in Grade 1, but the LoLT remains English, even in Grade 1 (ibid). Alidou, Boly, Brock-Utne, Diallo, Heugh \& Wolf ( 2006) report that even in the new South Africa, African languages appear to be gradually ceding importance to the English language. The dominant use of English in schools is a natural historic process, owing to the status of English in society. Bamgbose (2005) observed two stages of decreased use of a black African language at schools: from 8 to 4 years during apartheid education 1977-1993; and from 4 to 3 years after the new democratic government introduced the Outcomes Based Education (OBE) curriculum in 1997.

To date, there has been a paucity of findings and recommendations in literature supporting the transition to English by the end of grade 3 or earlier. No recognised expert in psycholinguistics has suggested that switching from the first language (mother tongue) as LoLT to English by the end of grade 3 will enable learners to perform well across the curriculum (Alidou, et.al, 2006). Research has indicated that learners who had used their mother tongue as LoLT to the end of primary school (7 years), followed by dual medium of Afrikaans-English (grades 8-12), performed better than learners with monolingual Afrikaans, or monolingual English. Studies conducted by Bamgbose (2000) indicate that learners who had 6 years of their mother tongue as LoLT performed better in the English subject as well as other content subjects. Bamgbose (2005) argues that three years of the mother tongue as LoLT at school is not adequate. From 1976 onwards, the pass rate of grade 12 learners has been dropping, due to the substitution of L1 as LoLT with English by the end of grade three (ibid). For example, the pass rate of learners in this grade, dropped from $83,7 \%$ in 1976 to $44 \%$ in 1992 (Alidou,et.al 2006). From grade four onwards, the achievement of these learners dropped significantly in relation to the national standard (ibid). Alidou, et.al, (2006) argue that the longer the L1 of learners is retained at school as a LoLT, the better the performance in mathematics, science and technology. Collier and Thomas (2004) confirm the findings of the USA study (Alidou, et.al 2006) by indicating that the benefits of dual -medium instruction models narrowed the gap in performance between L1 and L2 learners of English.

Bamgbose (2005) argues that the fallacy that proficient competence in English can only be achieved if it is used as a language of teaching and learning is part of the colonial legacy of South Africa". Baker (2002) agrees that immersing children in an English school or replacing their first language with English has never worked anywhere in helping children to perform. Competence in the language of instruction on the part of both teachers and learners is crucial for effective teaching and learning. According to the DoE (2008: 8), the majority of South African teachers do not possess the necessary knowledge and skills to support English language learning and to teach literacy skills across the entire curriculum. Howie (cited in Blaine, 2007) attributes the poor literacy in English in South Africa to the fact that many primary school learners experience reading problems due to the poor reading skills taught at school. He further argues that poor literacy results cannot be solely attributed to second-language instruction as teachers and learners are struggling with literacy in the African languages as well as in the English language. Learning difficulties in English are the most well-founded and serious indictment of the education system as a whole in rural South Africa. The low levels of language proficiency in English among learners have been a long-standing defect with which teachers and academics have been grappling as they attempt to provide quality education (Neeta and Klu, 2013). In order to address some of the challenges of facilitating effective communication between students and teachers in the classroom, code switching from mother (L1) to English (L2) is used in most of the classroom.

\subsection{Code Switching as a communicative strategy in ESL classrooms}

Code switching is a term used when switching between two languages among the bilinguals and multi-linguals. According to Kumar \& Narendra (2012), code switching is a linguistic phenomenon claimed to be the most prevalent and common mode of communication among the bilingual speakers. Magid \& Mugaddam (2013) assert that code switching can take place in a conversation when one speaker uses one language and the other speaker answers in a different language. According to Gulzar, Farooq \& Umer (2013), teachers switch code as a strategy to compensate the deficiency on the part of students. It is well known that, communication in English can be a barrier for many second-language learners because English serves both as a content subject and also as the means of pedagogic interactions in classrooms (Brice, 2001, p. 8). Martin-Jones (2003, p. 6) explains that

"Bilingual teachers and learners routinely use code-switching as an additional meaning-making resource within the ongoing flow of classroom talk. Code-switching is used to demarcate different kinds of discourse: to signal the transition between preparing for a lesson and the start of a lesson; to distinguish classroom management talk from talk related to lesson content; to specify a particular addressee; to change footing or to make an aside or to distinguish the reading aloud of a text from talk about the text"

Code switching may be used as an effective teaching strategy for second language learning (Gulzar, Farooq \& Umer 2013). The function of code-switching is to allow the students to become autonomous over a period of time 
whereby the teaching is reciprocated from the teacher to the student (ibid). The use of code-switching in the classroom would provide for a bilingual norm and is seen to be an acceptable method of communication. Students then would feel comfortable switching languages within normal conversations providing for a bilingual society. It has also been outlined that code-switching may facilitate language development as a mechanism for providing language samples and may also be utilised as a teaching method for teaching second language. Studies seem to suggest that teacher code switching, whether in teacher-led classroom discourse or in teacher-student interaction, may be a sophisticated language use serving a variety of pedagogical purposes. Yet, some researchers called for occasional and judicious use of L1 in L2 classes to avoid over use of L1 ( Hidayati, 2012; Neeta \& Klu, 2013; Weschler, 1997). Studies found that code switching to students' L1 in the ESL classroom served hybrid useful functions that expand negotiation, understanding and hence interaction in the classrooms. Code switching in ESL classrooms might be considered an interactional resource that is used by both teachers and students in the process of understanding each other (Ustunel and Seedhouse, 2005). Awad El Karim (2003) in Sudan found that, Code switching is an actively positive and effective strategy in classroom discourse. In L2 literature it is maintained that focus on meaning will help students to approximate L1 acquisition conditions and may even lead to similar success in the L2. In this case code switching can help students use their L1 to elicit language meaning and encourage peer discussion to maximize L2 meaning comprehension (Brown, 2000; Larsen-Freeman, 2000; Pica 2000)

\section{Research Methodology}

In this study, both quantitative and qualitative methods were employed. A questionnaire was used to collect quantitative data from as many educators at selected schools as possible within a short period. The interviews with Technology subject specialists were conducted to support and substantiate data obtained from the questionnaire.

\subsection{Participants and study context}

According to the continuous assessment (CASS) register for Technology in October 2007, there were 320 General Education and Training (GET) schools in the King Sabata Dalindyebo district of the Eastern Cape. The population consisted of 117 urban schools and 203 rural schools.

Twenty three (20\%) of the 117 urban schools were selected in a simple random sample. A sample of 41 of the 203 rural schools was used in the study. The study covered a total of 64 schools. The Grade 9 Technology teachers in each of the selected schools answered the questionnaires; however, only 57 teachers from 57 schools responded to the questionnaire.

Semi-structured interviews were employed to elicit responses from five Technology specialists for the GET band concerning the use of the English language in class discussions of Grade 9 learners in the King Sabata Dalindyebo district. The subject specialist were selected purposively on the basis of their expertise in subjects technology and use of LolT in the classroom. The subject specialists interact with the teachers and learners daily by monitoring and assessing their performance. Three subject specialists were from rural area while two of them were from urban location. These interviews were conducted 'face to face' with the Technology specialists at their offices on different 'prearranged' dates.

\subsection{Data collection and analysis}

A questionnaire with response options on a four-point Likert-type scale was developed for this study. The themes covered in the questionnaire included educators' views on the use of English in teaching Technology; whether learner participation is better when taught in the home language; and code switching to the home language when teaching the said subject. These themes were informed by the literature review which shaped this research concerning the use of English language as a medium of instruction (Mol) in the classrooms. In addition, provision was made in the questionnaires for respondents to express themselves with regards to issues of concern in response to open-ended questions.

The coded responses of the quantitative data obtained from the questionnaires were captured and presented in the form of a computer spreadsheet. In the discussion of the Likert scale responses, the positive responses ('Strongly agree' and 'Agree') were collapsed and summated. This was likewise performed for the negative responses ('Strongly disagree' and 'Disagree').

The data obtained from the interviews were analysed qualitatively, which requires a systematic selection, categorisation, comparison, synthesis and interpretation of the data in order to furnish an explanation of a single phenomenon of interest (White, 2005). Each of the responses to the open-ended questions in the interviews was summarised. All the respondents were afforded an opportunity to voice their personal views during the interview. 


\section{Findings and Discussion}

In order to determine the commonality of the challenges of using English in the teaching and learning of technology, a sample was selected as explained earlier. Of this sample, 36 questionnaires were returned from the rural areas and 21 from the urban areas. The responses of educators were categorised and summarised accordingly. The data is discussed according the statements posed in the questionnaire and linked with the theoretical perspectives. The findings were further explored during the interviews conducted with technology education specialists.

\subsection{Quantitative data}

Table 1. Summary of the findings on the use of English and the home language

\begin{tabular}{|c|c|c|c|c|}
\hline Statement & \multicolumn{2}{|c|}{ Strongly agree / Agree } & \multicolumn{2}{|c|}{ Strongly disagree / Disagree } \\
\hline & Rural & Urban & Rural & Urban \\
\hline Teachers don't use English regularly as a medium to teach Technology lesson in Grade 9 & $91.6 \%$ & $95.3 \%$ & $8.5 \%$ & $4.7 \%$ \\
\hline $\begin{array}{l}\text { Learners' participation is not good in Technology lessons when English is used compared to } \\
\text { when home language is used in teaching }\end{array}$ & $77.7 \%$ & $57.1 \%$ & $19.5 \%$ & $38.1 \%$ \\
\hline $\begin{array}{l}\text { Teachers code switching to home language when teaching Technology, to facilitate learners' } \\
\text { understanding }\end{array}$ & $86.1 \%$ & $28.6 \%$ & $13.9 \%$ & $71.4 \%$ \\
\hline
\end{tabular}

Table 1 indicates statements that represent challenges that teachers experience during the teaching of Technology. These statements reflect challenges because if learners don't communicate and participate in English as medium instruction, they will eventually be unable to express and articulates well in English, hence perform poor in the subject. One of the critical outcome of education is that learners should be able to communicate effectively using appropriate symbolic and/or language skills in various modes (Department of Basic Education, 2011).

The majority of respondents (91.6\%) from rural schools and 95,3\% from urban schools agreed that they don't use English regularly as a medium of instruction when teaching technology lessons. In contrast, others (13.2\%) stated that using English as a medium of instruction complicates the teaching of Technology subject because learners in the rural schools prefer their home language as a medium of instruction. As a result, teachers do most of the talking while learners sit silently or become passive participants during the rest of the lessons (Alidou, 2003; Rubagumya, 2003). However, the ability of learners to express themselves in English as a language of teaching and learning gives them pride. The pride in learners is based on the fact that English is associated with future economic and social welfare (Neito, 2000). There is also the view that "students who speak home language instead of English are perceived as 'handicapped' and they are urged, through both subtle and direct means to abandon their home language" (Neito, 2000).

Most of the teachers from both rural and urban schools (77.7\% and $57 \%$ respectively) agreed that students participate actively in the classroom when the teacher uses their home language in teaching and learning. This was not different from the findings of the study conducted by Alidou and Maman (2003), which found that when learners are taught in their African language, they are more active than when taught in English. To reiterate this point, Chekaraou ( 2004) who conducted a comprehensive study in Niger, reports that in a class where the home language was predominant "the entire class wanted to participate so much that they would stand up from their seats, move towards the teacher and wanting to be called upon to answer questions" (Chekaraou, 2004).

The majority of the respondents (86.1\%) from the rural schools and less than half $(28.6 \%)$ from the urban schools agreed that code switching should be employed. This is confirmed by other studies (e.g. Probyn, 2006), in which teachers used code switching to isiXhosa as a support strategy to enable learners to understand concepts. However, in this study most teachers (71.4\%) from urban schools disagreed with code switching. This is not surprising, because in urban areas (townships and suburban areas), people are multicultural and multilingual due to the historical background of the colonial and apartheid systems where many people from different African cultures lived together in metropolitan areas (Johannesburg and Pretoria).

\subsection{Qualitative data}

The results indicate that in both urban and rural schools, a large number of educators prefer to use English as a medium of instruction in the classroom. The subject specialists rated the ability of Technology teachers to use English as an LoLT in the classroom as "fair". However, one technology specialist said: "The poor level of English on the part of the learners makes it difficult for the teachers to communicate freely and also use the English medium effectively to teach." They further indicated that the challenge is not limited to Technology educators, but rather for most teachers in the GET schools. This utterance with regards to technology is not different from other similar studies (Kaphesi, 2003), which agreed that retaining English as the LoLT from the lower grades creates teaching and learning problems in African schools.

Although teachers use English to teach Technology, students do not necessarily understand it. This is confirmed 
by other research findings in South Africa (Howie, 2001) that English frequently creates a barrier to learning when it is not the learners' home language. This problem can be attributed to two reasons: (1) learners have very little exposure to English outside the classroom (Probyn, 2006) and (2) teachers had received no or little training to teach through the medium of English (Alidou, et.al, 2006). The questionnaire responses as well as the interviews indicate that it appears that teachers use English in the classroom even though learners do not understand them. This becomes a vicious cycle of continuously producing future teachers who cannot communicate effectively with learners in the classroom. The results further indicate that the participation of learners in a classroom where technology is being taught is minimal unless they are allowed to use their home language.

\subsubsection{Students' participation in technology lessons when using the home language}

The interview question which teachers were asked to respond was "What is the ability of learners to participate in group discussions using English language? The responses of the respondents indicate a disparity between the rural and urban schools, once again revealing the impact of the rural-urban divide with regard to the student levels of literacy in English. Some respondents from the urban schools commented in the questionnaire that learners in their schools have a good foundation in English because the schools are English-medium. On the other hand, others commented that English remains a barrier to learner participation in the classroom. The challenge here is that only a few students are able to participate in the lesson while others become passive receivers of knowledge. This defeats the objective of active learning, that is, to involve all learners in classroom activities. Studies conducted by Setati and Barwell (2006) confirmed that students participate better in the discussion if they are also allowed to express themselves in their home language. This is supported subject specialist during interview who says" ...that most learners in the rural schools can hardly speak a full sentence in English. For example, Setati and Barwell refer to a student who asked the teacher to express himself/herself in Setswana. In that classroom, the teacher enabled students to participate freely in the discussion. In another study (Probyn, 2004), it was found that approximately 85\% of the time, the teacher code switch to isiXhosa. The teacher's lesson consisted of reading a portion of English from the textbook, and then translating and explaining it in isiXhosa. Myburg et al. (2004) also observed that whenever a genuine communicative need arose, the students automatically and instantly resorted to the use of their home language. Myburg et al. observations is supported by the utterance of Technology specialist when saying "Learners simply refuse to speak when discussions are made in English but they participate well when discussions are done in their local language". A lack of insight into what is being taught in class leads a student to feel helpless and despondent. This is supported by a comment made by a learner in the Myburg et al study: "I feel lost. The teacher stands there and explains and I'm the one that does not understand". The Technology specialists unanimously responded during an interview in the current study, that in most of the schools that they visit, particularly in the rural areas, students hardly use English during class discussions. The Technology specialist said: "In many Black people schools, the inability of teachers and learners to understand each other in English compels teachers to teach in vernacular" According to Myburg et al. (2004), schools are unable to adjust to individual differences of students; hence children face daily depreciation in their learning performance. Consequently, many children drop out of school early. One of the strategies used to assist learners in understanding technology is known as 'code switching', which is popular in many science and mathematics classrooms (Setati \& Barwell, 2006).

\subsubsection{The teachers rationale for code switching to a home language when teaching technology}

Teachers were asked an interview question: To what extent is code switching to home language used when teaching technology? Although switching from English to the home language (code switching) when teaching enables educators to express themselves confidently and learners to participate in the lesson, 'code switching' is not possible in classes where teachers cannot speak the home language of the learners. Hence, 'code switching' in most of the urban schools will be impossible. However, in the rural schools, $88.9 \%$ of the respondents in the current study stated that they can speak the vernacular. Hence 'code switching' is practised more frequently in the rural schools than in the urban ones, because of unicultural class. Although 'code-switching' is common in many of the black South African classrooms, it is not permitted to be used all times. In a study carried out by Mwinsheikhe (2003) in Tanzania, in an interview, the teacher said: "I personally was compelled to switch to Kiswahili by a sense of helplessness born of the inability to make students understand the subject matter by using English." Teachers 'code-switch' in order to facilitate learning as well as to create a more relaxed atmosphere in class (Mwinsheikhe, 2003).

One of the respondents in the present study commented: "I switch to vernacular when teaching Technology to facilitate learners' understanding." Teachers encouraged learners to use isiXhosa if they experience difficulty when answering in English. Similarly, in a study conducted in schools in Botswana, it was found that code switching to seTswana was inevitable because learners did not understand English, even if the educator tried to explain in English 
(Kasule \& Mapolelo, 2005). Lack of understanding English language appears to be a barrier in performing in key subjects such as mathematics, science and technology, as this was supported by one of the Technology specialist in an interview when saying: "learners language competency affects their performance in all subjects, at all grades poor language competence limits conceptual understanding". This utterance is in agreement with parents concern that children fail because of lack of understanding the subjects (Motshekga,2011). Further, Professor Rollnick also supported the Technology specialist when she says that the majority of South African leaners will not be able to answer many of the science questions because of the language demand (Child, 2012).

Alidou, et al. (2006) argues that teachers switch codes because they are unable to express themselves fluently in English. This is supported by technology specialist who said: "However, in most of the rural schools, teachers use the home language to teach, since some of the teachers are not able to express themselves fluently in English language". All the subject specialists who were involved in this study indicated that code switching is common in schools, and that it is not peculiar to Technology teachers only. The Technology specialist gave reason for code-switchibg by saying: "Nevertheless, there are situations where teachers have to result to code-switching and use the home language to facilitate learners' understanding". In all the other learning areas, they stressed that teachers resort to code switching (Setati \& Barwell, 2006; Probyn, 2004; Setati, Adler, Reed \& Bapo0, 2002).

However, the decision to use 'code-switching' is not an easy task for the teacher as Adler (2001) observed an ongoing dilemma in the classroom with regard to 'code switching' between the mother tongue of the learners and the LoLT, that is, English.

\section{Conclusion and Recommendations}

Several studies on the use of English in teaching and learning indicate that there are still communication barriers to understanding science and technology subjects when English language is used as the Mol. It has also been shown that despite the good intention of the school language policy (LiEP) to promote black South African languages, English remains the dominant language in South African schools. Parents from black communities are interested in their children being taught Science and Technology in English, even in the lower grades. Teachers should employ 'code-switching' as a strategy to understand the subject with great care, because if code switching to the home language is used too often, it may deprive students of communicating and writing using English language, both in the classroom and outside. Based on the arguments advanced in this study concerning the role that a mother-tongue language plays in the learning and development of the child, the following recommendations are made: (1) The ministry of basic education should develop a communication or advocacy strategy which informs and engages parents with regard to language for learning and development debates; (2) black African languages should be used as LoLT to at least the end of grade/year 6; (3) bilingual programmes where English and the L1 of learners is used on a 50/50 basis, LoLT should be commonly employed at school; and (4) assessors of literacy and numeracy in African settings should possess appropriate expertise in biliteracy and bilingual development throughout primary school, that is, language acquisition and or psycholinguistics and applied linguistics. Teacher education programmes should be revised to integrate bi/multilingual education needs of bilingual teachers. The problem of student participation at higher education institutions is also serious due to the inability of students to express themselves in English. Teacher education programmes should integrate multilingual and intercultural education philosophies, theories and methodologies in the initial and continuous professional teacher development. Such initiatives will help teachers become familiar with first and second language acquisition as well as teaching theories and methodologies.

\section{References}

Adler, J. (2001). Teaching Mathematics in Multiligual Classrooms. Dordrecht: KluwerAcademic Publishers.

Alexander N. (2001). Language policy, symbolic power and democratic responsibility of the post-apartheid university. Paper presented at the DCS Oosthuizen Memorial Lecture. Rhodes University, Grahamstown, 9 October 2001.

Alidou, H. \& Maman, M.G. (2003). Assessment and observations of experiences of utilisation of African languages in Basic Education. Working paper for the ADEA Biennial meeting 2003. Grand Baie, Mauritius, 3-6 December, 2003.

Alidou, H. (2003). Medium of instruction in post-colonial Africa. In: Tollefson, JW \& Tsui, A (Eds). Medium of instruction policies: which agenda? Whose agenda? Pp. 195-214. London: Lawrence Erlbaum.

Alidou, H. Boly, A. Brock-Utne, B. Diallo, Y.S. Heugh, K. Wolf, E. (Eds). (2006). Optimising

learning and education in Africa - the language factor. Working document on stock-taking research in mother tongue and bilingual education in sub-Saharan Africa.

Awad El Karim, A. A. (2003). Discourse strategies and dynamic analysis of code-switching as an ongoingmeaning-negotiation process. Unpublished Ph. D. Thesis, University of Khartoum, Sudan.

Baker, C. (2002) (Eds). Foundations of bilingual education and bilingualism. Clevedon: Multilingual Matters.

Bamgbose, A. (2005). Mother tongue education. Lessons from the Yoruba experiences. In:

Brock-U-Utne, B., \& Hopson, RK. (eds). Languages of Instruction for African Emancipation: focus on postcolonial contexts and consideration, 210-234. Cape Town: CASAS; Dar es Salaam: Mkuki na Nyota. 
Bamgbose, A. (2000). Language and exclusion: the consequences of language policies in Africa. Munster:LIT.

Blaine, S. (2007). Multilingualism 'masks deficient teaching of reading'. Business Day, Jun. 1:1.

Brice, A. (2000). Code switching and Code mixing in the ESL Classroom: A Study of Pragmatic and Syntactic Feature. Advances in Speech Language Pathology. Journal of the Speech Pathology Association of Australia, 20(1), 19-28.

Brock-Utne, B. (2005). Language-in-education policies and practices in Africa with a special focus on Tanzania and South Africa - insights from research in progress. In: Lin, AMY., \& Martin, P. (eds). Decolonisation, globalisation, language in education. 175 - 195. Toronto: Multilingual Matters.

Brock - Utne, B. Desai, Z. \& Qorro, M. (eds). (2004). Researching the language of instruction in Tanzania and South Africa. Vlaeberg: African Minds.

Brown, H. D. (4th edition). (2000). Principles of language learning and teaching. Englewood cliffs NJ: Prentice Hall Reagents.

Chekaraou, I. (2004). Teachers' s appropriation of bilingual education reform policy in sub-Saharan Africa: a socio-cultural study of two Hausa-French schools in Niger. PhD. thesis. Bloomington: Indiana University.

Child, K. (2012). Science teachers failing- professor says pupils not taught to understand and apply maths, science. The Times: Monday 5 November 2012.

Collier, V. \& Thomas, W. (2004). The astounding effectiveness of dual language education for all. BABE Journal of Research and Practice, 2(1) Winter.

Dalvit, L \& de Klerk, V. (2005). Attitudes of Xhosa-speaking students at the University of Fort Hare towards the use of Xhosa as a language of learning and teaching (LOLT). Southern African Linguistics and Applied Language Studies 2005, 23(1): pp. 1-18

Department of Education (DoE). (2008). National Reading Strategy. Pretoria: Government Printers.

Dlamini, C.R.M. (2001). The attainability of multilingualism at university. Aambeeld/Anvil 29 (1): 33-36

Dutcher, N. (ed). (2004). Expanding educational opportunity in linguistically diverse societies. Washington DC: Center for Applied Linguisitics.

Ferreira, J.G. (2011). Teaching Life Sciences to English second language learners:what do teachers do? South African Journal of Education, 31(1): 102-113.

Fredua-Kwarteng, Y. \& Ahia, F. (2005). Ghana flunks at maths and science: analysis (1). Feature article. Ghana News 23 February.

Gulzar, M.A, Farooq, M.U. \& Umer, M. (2013). Inter-Sentential Patterns of Code-Switching: A Gender-Based Investigation of Male and Female EFL Teachers. International Education Studies, 6 (11), pp. 144-159

Heugh, K. (2000). The case against bilingual and multilingual education in South Africa. PRAESA occasional paper No 6. Cape Town: PRAESA.

Hidayati, I. S. (2012). Evaluating the role of L1 in teaching receptive skills and grammar in EFL classes. Indonesian Joumal of Applied Linguistics, Vol. 1(2), pp 17-32.

Kasule, D. \& Mapolelo, D. (2005). Teachers' strategies of teaching primary school mathematics in a second language: a case of Botswana. International Journal of Educational Development, 25:602-617.

Kumar, N.S \& Narendra, M. (2012). A study of code switching in relation to ESL. Langauge in India. V (12), pp. 57-61.

Larsen-Freeman, D. (2nd edition). (2000). Techniques and principles in second language teaching. Oxford: Oxford University Press.

Luckett, K. (1995). National additive bilingualism: towards a language plan for South African ducation. In: Heugh K, Siegruhn A \& Pluddemann P (eds) Multilingual Education for South Africa. Isando: Heinemann Publishers Ltd. pp 73-79.

Martin-Jones, M. (2003). Teaching and Learning Bilingually: Towards an Agenda for Qualitative Classroom -based Research. Retrieved on 03 May 2013 from http://www.aber.ac.uk/mercator/images/marilyn.pdf

Magid, M.M.A. \& Mugaddam, A.H. (2013). Code switching as an interactive tool in ESL classroom. English Linguistic Research. 2 (2), pp 31-42

Mekonnen, A.G. (2005). Socio-cultural and educational implications of using mother tongues as languages of instruction in Ethiopia. Master's thesis. University of Oslo.

Motshekga, A. (2011). Parents, teachers to blame. The Times. 19 August: p7.

Myburg, O. Poggenpoel, M. \& Van Rensburg, W. (2004). Learners's experience of teaching and learning in a second or third language. Education. Johannesburg. University of Johannesburg. Retrieved October 23, 2010, from http://findarticles.com/p/articles/mi_3673/is_3_124/ai_n29092878.

Muyeeba, K.C. (2004). Challenges of making and implementing policy in the multilingual state of Zambia. In : Joachim FP (ed). Making multilingual education a reality for all, pp. 167-176.

Mwinsheikhe, H.M. (2003). Science and the language barrier: using Kiswahili as a medium of instruction in Tanzania secondary schools as a strategy of improving student participation and performance in science. In: Brock-Utne, Desai, Z., \& Qorro, M. (Eds). Language of instruction in Tanzania and South Africa (LOITASA), pp. 129-149. Dar es Salaam: E \& D Publishers.

Neeta, N.C \& Klu , E. K . (2013). Teachers' Professional Knowledge Competence and Second Language Education in South Africa. International Journal of Educational Sciences. 5(3): 255-262

Neito, S. (2000). Affirming diversity. The sociopolitical context of multicultural education. New York: Addison-Wesley Longman.

Pica, T. (2000). Tradition and transition in English language teaching methodology. System, 28, pp 1-18.

Probyn, M. (2004). Making sense of science through two languages: a South African case study. School Science Review, 86 (314):49-59.

Probyn, M. (2006). Language and learning science in South Africa. Language and Education. 20 (5), 391-414.

Rubagumya, C. (2003). English medium primary schools in Tanzania: a new linguistic market in education? In: Brock-Utne B, Zubeida D \& Qorro M. Language of instruction in Tanzania and South Africa, pp. 149-170.

Reddy, V. (2005). State of mathematics and science education: schools are not equal. PretoriaHuman Sciences Research Council, South Africa.

Setati, M. \& Adler, J. (2001). Between languages and discourses. Language practices in primary multilingual mathematics classrooms in South Africa. Educational Studies in Mathematics, 43:243-269.

Setati, M. \& Barwell, R. (2006). Discursive practices in two multilingual mathematics classrooms: an international comparison. African Journal of Research in SMT Education, 10 (2):27-38.

Setati, M. Adler, J. Reed, Y. \& Bapoo, A. (2002). Incomplete journeys: code-switching and other language practices in mathematics, science and English language classrooms in South Africa. Language and Education, 16:128-149.

Titlestad, P. (1996). English, the Constitution and South Africa's language future. In: De Klerk V (ed) Focus on South Africa. Amsterdam: John Benjamins. pp 163-173.

Webb, V.N \& Kembo-Sure, J (eds). 2000. African Voices: an Introduction to the Languages and Linguistics of Africa. Oxford: Oxford University Press.

Weschler, R. (1997). Uses of Japanese (L1) in English classroom: Introducing the Functional-translation Method. Internet TESOL Journal 3(2). Retrieved from http://www. aitec.ac.jp/iteslj.

Wilmot, E.M. (2003). Who gains when policy fails? Implications of the suspensions of Ghana's school language policy. Paper presented at the CIES- MidWest conference, 2003.

White, C. (2005). Research: a practical guide. Pretoria: Ithuthuko Investment.

Wright, L. 1996. The standardisation question in black South African English. In: De Klerk

V (ed) Focus on South Africa. Amsterdam: John Benjamins. pp 149-162.

Ustunel, E. \& Seedhouse, P. (2005). Why that, in that language, right now? Code-switching and pedagogical focus. International Journal of applied Linguistics, Vol. 15(3),302-325. 